\title{
Afectividad ambiental: Sensibilidad, empatía, estéticas del habitar
}

Giraldo, O. F.; Toro, I. (2020) Afectividad ambiental: Sensibilidad, empatía, estéticas del habitar. Chetumal, Quintana Roo, México: El Colegio de la Frontera Sur: Universidad Veracruzana.

Comentario a cargo de: Natalia Barraco Mastrangelo

Lic. en Ciencias de la Educación por la Facultad de Humanidades y Ciencias de la Educación (Udelar). Magíster en Educación por la Universidad de Campinas (Brasil) y en Políticas Públicas para la Gestión Educativa y el Desarrollo Social del Centro de Cooperación Regional para la Educación de los Adultos en América Latina y el Caribe, (CREFAL), México. Integrante del Departamento de Historia y Filosofía de la Educación (FHCE- Udelar). Encargada de la Unidad de Planeamiento y Gestión Educativa del Centro

de Formación Penitenciaria (CEFOPEN) del Instituto Nacional de Rehabilitación (INR), Uruguay. Integra desde 2009 líneas de investigación sobre aspectos vinculados a la ética, filosofía de la educación y el cuidado aplicado a problemas de la educación contemporánea. Participa del grupo CSIC-Udelar "Emociones, narraciones y ciudadanía". Desde 2010 se dedica a la gestión vinculada a proyectos educativos y políticas educativas, desde el 2014 vinculada al desarrollo de propuestas formativas para el personal penitenciario uruguayo. Participa activamente desde el 2018 en la Mesa interinstitucional de educación para personas en conflicto con la ley penal.

Este libro, a pesar de no estar directamente dirigido a educadores, perfectamente podríamos tomarlo como una invitación a pensar la educación contemporánea en términos de desafíos para habitar el mundo de todos los que nos desempeñamos como tales. "Afectividad ambiental: Sensibilidad, empatía, estéticas del habitar", publicado en octubre del 2020, en pleno contexto de la pandemia del Covid-19, convoca a pensarnos desde una ética ambiental que no sólo trate los aspectos político-económicos, culturales, materiales y tecnológicos sino, sobre todo, aborde las dimensiones "afectiva, sensible, sintiente de nuestro estar en el mundo". Para los autores es crucial atender a la concepción (y formación) de nosotros mismos como habitantes-ciudadanos del mundo y, por lo tanto, como agentes co-creadores de ambientes que empatizan, cuidan y preservan. Habitar, implica un compromiso ético. No se trata de permanecer en espacios pasivos, sino que es necesario disponer de una escucha activa y un diálogo con el lugar habitado. Habitar es sentir la experiencia vital de un mundo vivo. En este sentido, el libro aborda un tema fundamental que nos ha interpelado principalmente en pandemia y con los asuntos de la ecología política y la ecosofía: la interdependencia, la empatía y la convivencia. Para eso, es importante desmitificar las relaciones dicotómicas o binarias de sociedad versus naturaleza y del pensar versus sentir, para realizar un abordaje en clave de trama y de interconexión, dando paso a una cartografía de los afectos que impliquen sincronía con los ciclos vitales del planeta.

Mucho se habla de ecología, pero poco hablamos en la educación de lo que implicaría una educación ambiental pensada desde una perspectiva ética e integradora que involucre una sensibilidad empática comprometida con el mundo y con los otros. Sabemos que el desafío siempre vigente de la educación y particularmente en tiempos contemporáneos es la convivencia, el aprender a vivir juntos. Dicho desafío necesariamente requiere del desarrollo de la sensibilidad, de la ética y de la afectividad que convocan los autores a pensar como urgente. Giraldo y Toro remiten a que es hora de deconstruir la llamada civilización industrial y el paradigma racional para cultivar lo sensible, lo que implica, sin dudas (otra vez) lo educativo. Aquí hay otro desa- 
fío fundamental para educadores contemporáneos: aquello que involucra una educación de las emociones y de los sentidos. Nuestras matrices de aprendizaje cartesianas han priorizado y hegemonizado formas de ser y estar en el mundo por lo que vivir en clave de trama necesita de una nueva concepción que integre de manera indisociable la cuestión epistemológica (del saber) y la epistemofílica (del sentir). Inaugurar este ethos, supone hablar de la epistemo-estesis, una ontología de la vida que responde a nuestra estancia terrestre en la inconmensurabilidad del cosmos, rompiendo el antropocentrismo y la relación moderna sujeto-objeto para tener en cuenta la forma en la que nos encontramos y la forma en la cual somos afectados por dichos encuentros. Por lo que promover cambios en esta educación ambiental, también implicaría desmitificar la concepción de que educar en la sensibilidad se reduce a formar personas susceptibles, que presentan debilidad o escisión con el pensamiento crítico. Ser sensibles es ser responsables de lo colectivo, es decir, experimentar una ética de saber convivir.

\section{Inaugurar una ética del saber-habitar}

"El reto implica hallar distintas puertas para ejercitar la sensibilidad, hasta descubrir que somos cuerpos entre cuerpos, mundos entre mundos, resultados entre múltiples encuentros de pieles: inter-seresinter-estando" (2020: p. 55).

Al referirse a la ética del saber-habitar, los autores explicitan la necesidad de no incurrir en reduccionismos, idealizaciones o confusiones con la moral. Y agregan otra advertencia: la ética del saber-habitar no persigue la perfectibilidad humana, ni es esencialista. Supone, al contrario, comprender nuestras sombras, nuestros claroscuros, porque lo humano también es el horror, la guerra, la violencia, las lógicas del mercado, la lucha por la sobrevivencia, las desigualdades e injusticia social y la forma en la cual abordamos/promovemos la enfermedad y la muerte. Todas, afectividades que nos destruyen, nos someten, nos sumergen en el peor estado. En este sentido, la ontología relacional aborda la complejidad, asumiendo que el "sentirse perteneciente" no siempre implica consenso o acciones éticas sin contradicciones o fisuras (2020:111). La ética ambiental, más que enunciarse, se pronuncia a través del encuentro, se descubre a través de la exploración del cuerpo y rescata las sabidurías ancestrales y saberes ambientales de los pueblos originarios, promoviendo, de alguna forma un pensamiento decolonial. Asimismo, otra característica fundamental, es que no se habla de cálculos, teorizaciones o mapas racionales donde se fuerza a las personas a ser empáticas, la empatía no se obliga ni se obedece ante una imposición moral, sino que se sostiene en la disposición de ser afectadas por el encuentro con los otros seres del mundo. El ethos rompe con la superioridad moral o la imposición del deber ser con la pretensión de instalar una geografía del contacto, una ética que incluye capacidades de poder ser y hacer, una ética de posibilidades y de potencias subjetivas e intersubjetivas. Por eso, la empatía es precondición de la ética ambiental y percepción para la acción ética, es una capacidad afectiva y cognitiva básica que nos impulsa a movilizarnos para buscar el bienestar de la alteridad.

Por todo lo anterior, no quedan dudas que los autores nos regalan la oportunidad de inaugurar una ética y estética del saber-habitar, una topofilia, -como le llamó Bachelard-, un amor con nuestro lugar en el mundo, nuestro mundo. $Y$ encontrarnos con nosotros mismos, con el micro y macrocosmos, con los otros. Encontrarnos en un territorio existencial donde podamos desarrollar nuestra capacidad de sentirnos interconectados y habitar desde una sensibilidad que nos conecte con el bienestar colectivo, con una nueva forma de vivir y por qué no, de habitar la convivencia. Volvemos a hacer otro guiño para los colegas educadores, insinuando que educar en esta ética del saber-habitar supone asumir las emociones propias y el desarrollo de la capacidad empática como condición política y filosófica. Condición que posibilite promover la formación de personas que se preocupen por el bienestar de la alteridad y nos empuje a superar (no sustituir) la educación moral de la que somos hijos. Celebramos entonces, las ideas de este libro, con el fin de asumir nuestra topofilia, nuestra capacidad de empatía y emprender el desafío de desarrollar propuestas de formación de nuevas ciudadanías, sensibles y empáticas. Para habitar un mundo de todos y para todos, desde la promoción y reinvención de climas educativos proclives para el desarrollo de esta sensibilidad, una educación para los encuentros que priorice la convivencia comprometida con los nudos del cohabitar.

Abordar nuestra "mala educación" emocional y ambiental o la ausencia de ésta y seguir las pistas de este libro, puede ser, quizás, un reto más para formar una ciudadanía menos violenta, menos impotente, menos desesperanzada y con poca empatía, asumiendo que los climas educativos no están necesariamente dados apriori sino que pueden ser creados, asumidos y habitados desde una ética ambiental dialógica, empática y sensible al colectivo. 